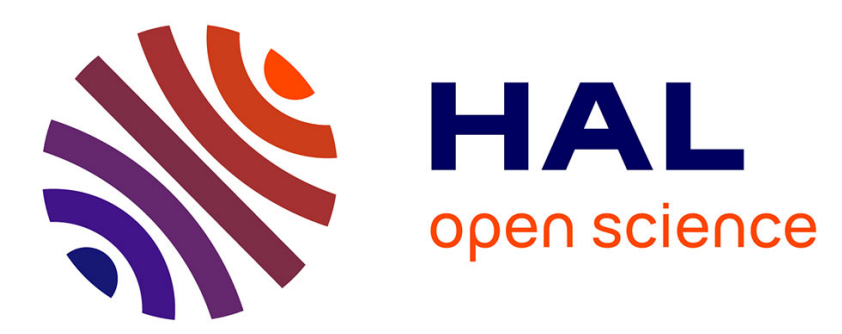

\title{
Human Body Communication Channel Modeling Using Vector Network Analyzer Measurement
}

Luca Petrillo, Julien Sarrazin, Hugues Libotte, Aziz Benlarbi-Delai, François Horlin, Philippe de Doncker

\section{- To cite this version:}

Luca Petrillo, Julien Sarrazin, Hugues Libotte, Aziz Benlarbi-Delai, François Horlin, et al.. Human Body Communication Channel Modeling Using Vector Network Analyzer Measurement. Conference EuCAP 2017, Mar 2017, Paris, France. hal-01511475

\section{HAL Id: hal-01511475 https: / hal.sorbonne-universite.fr/hal-01511475}

Submitted on 3 Sep 2019

HAL is a multi-disciplinary open access archive for the deposit and dissemination of scientific research documents, whether they are published or not. The documents may come from teaching and research institutions in France or abroad, or from public or private research centers.
L'archive ouverte pluridisciplinaire HAL, est destinée au dépôt et à la diffusion de documents scientifiques de niveau recherche, publiés ou non, émanant des établissements d'enseignement et de recherche français ou étrangers, des laboratoires publics ou privés. 


\title{
Human Body Communication Channel Modeling Using Vector Network Analyzer Measurement
}

\author{
Luca Petrillo ${ }^{1}$, Julien Sarrazin ${ }^{2}$, Hugues Libotte ${ }^{1}$, \\ Aziz Benlarbi-Delaï ${ }^{2}$, François Horlin ${ }^{1}$, Philippe De Doncker ${ }^{1}$ \\ ${ }^{1}$ OPERA Dept., Wireless Comm. Group, Université Libre de Bruxelles (ULB), B-1050 Brussels, Belgium,, lpetrill@ulb.ac.be \\ ${ }^{2}$ Sorbonne Universités, UPMC Univ Paris 06, UR2, L2E, F-75005 Paris, France
}

\begin{abstract}
Several studies have examined the propagation losses of the Human Body Communication (HBC) channel. However, a general agreement has not be found yet. In this paper, the complete S-matrix of the $\mathrm{HBC}$ channel is measured on an human subject using two kinds of electrode devices. The data is integrated in a lumped element model, which allows to take into account for the capacitive return path of realistic battery operated transmitter and receiver. Results, shown as power gain curves between $10 \mathrm{MHz}$ and $150 \mathrm{MHz}$, exhibit a band pass profile, with cut-off frequency depending on the kind of electrode devices. A model is obtained by vector fitting of the equivalent $Z$-matrix of the measured HBC channel.
\end{abstract}

Index Terms-Propagation, BAN, HBC.

\section{INTODUCTION}

In the field of Body Area Networks, Human Body Communication (HBC) is a technology that has been added to the IEEE.802.15.6 standard [1]. For a capacitive coupling scenario, both transmitter and receiver are battery powered small devices consisting in a signal electrode, i.e. an electrical conductor to be placed in contact with the body, and a ground electrode, i.e. the ground plane of the device. The signal is applied to the body by the transmitter signal electrode and sensed by the receiver electrode as a current flowing through receiver input resistance. This is the forward path of the signal. Since transmitter and receiver are battery powered, their ground planes are floating and the return path of the signal is capacitive. Both theoretical [2] and experimental [3], [4] investigations have been carried out to understand and predict HBC channels. Lumped element models have been proposed [5], while validation has been carried out using prototypes [6]. Concerning experimental investigations, baluns have been used to carry out Vector Network Analyzer (VNA) measurements while decoupling $\mathrm{HBC}$ return path from instrument ground plane [7]. However, the effect of this solution is the modification of the return path without being able to isolate HBC channel [8]. If the use of prototypes guarantee the preservation of the return path, it is time consuming, limited in frequency resolution and reproducibility is harder than using a VNA.

In this paper, we aim to show that a physical understanding of the mechanisms of HBC channel can be used to correctly interpret measurement results obtained with VNA. In particular, full 2-ports measurements are used in a model in order to take into account propagation and contact impedance between human body and signal electrodes. Return path is then modified by using capacitors in order to account for capacitive coupling with the external environment.

\section{General MODEL}

The proposed model is shown in Fig. 1.(a). The two-port network represents the direct path through the body and takes into account the effect of contact between signal electrodes and the skin, and propagation through the body, including leakage out of the body to ground. Return capacitors model the coupling to the environment.

The two-port network has been measured with a VNA R\&SZVL. Measurements were conducted during six days on the same male subject, $1.68 \mathrm{~m}$ height, $55 \mathrm{~kg}$ weight. Two coaxial cables R\&S ZV-Z193 $0.91 \mathrm{~m}$ length were used to connect test devices to the VNA. Full two-port calibration is performed. Devices consist of two 20x20 mm copper patches on FR4 boards, to obtain signal electrode and ground plane. Two kinds of devices were tested: patches separated by a $10 \mathrm{~mm}$ air-gap (Electrode 1) and patches printed on two sides of the same board, thus separated by $1.6 \mathrm{~mm}$ (Electrode 2).

Cables and devices were fixed to two wood tripods and measurement were performed while the test subject was touching the signal electrodes. Two measurement configurations were carried out: devices in contact with right and left wrists and devices in contact with the wrist and the upper-arm. Distances between devices were $120 \mathrm{~cm}$ and $30 \mathrm{~cm}$, respectively.

The complete S-matrix is measured for each configuration of for each pair of electrodes and repeated during the measurement campaign. The S-matrix is transformed to the Z-matrix and the circuit shown in Fig. 1.(b) is studied.

\section{Power Gain}

Power gain is considered to analyze the system [9]. By taking into account capacitive coupling between transmitter and receiver and the earth, as shown in Fig. 1.(b), the power into the load can be written as:

$$
P_{L}=\frac{1}{2} \frac{\left|V_{\mathrm{th}}\right|^{2} R_{L}}{\left|Z_{\mathrm{out}}+R_{L}+Z_{C L}\right|^{2}}
$$

where $Z_{11}$ and $Z_{21}$ are Z-matrix elements, $Z_{C G}$ and $Z_{C L}$ are return capacitor impedances and $Z_{\text {out }}$ is the impedance of the output side of the two-port network: 


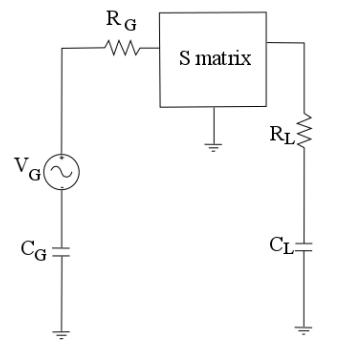

(a)

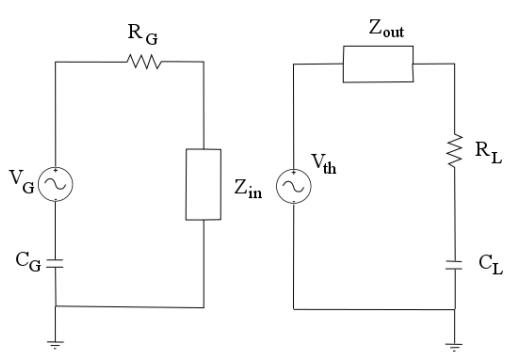

(b)
Fig. 1. (a) Circuit used to model HBC channel and (b) equivalent circuit using Z-matrix elements.

TABLE I

LUMPED ELEMENTS VALUES USED TO PERFORM SIMULATIONS

\begin{tabular}{c|c}
\hline \hline Element & Value \\
\hline$R_{G}$ & $50 \Omega$ \\
$C_{G}$ & $1 \mathrm{pF}$ \\
$R_{L}$ & $50 \Omega$ \\
$C_{L}$ & $1 \mathrm{pF}$ \\
\hline \hline
\end{tabular}

$$
Z_{\text {out }}=Z_{22}-\frac{Z_{12} Z_{21}}{Z_{11}+R_{G}+Z_{C G}}
$$

and $V_{\text {th }}$ is:

$$
V_{\mathrm{th}}=\frac{V_{G} Z_{21}}{Z_{11}+R_{G}+Z_{C G}}
$$

Clearly, $Z_{12}$ is always equal to $Z_{21}$ because of the reciprocity of the network. The transducer power gain is then:

$G_{T}=\frac{\text { power consumed by load resistance }}{\text { maximum available power from generator }}=P_{L} \frac{8 R_{G}}{\left|V_{G}\right|^{2}}$

$G_{T}$ has been calculated using measurement data and lumped elements values in Table I. The values of the capacitances depend on ground electrode surface and can be extracted from EM simulations [5].

Power gain curves have been calculated using model in [5] for distances between devices equal to $30 \mathrm{~cm}$ and $120 \mathrm{~cm}$. Electrodes inter-capacitance $C_{e}$ has been calculated and inserted in the model. For Electrode $1 C_{e}=0.8 \mathrm{pF}$ and for Electrode $2 C_{e}=9.4 \mathrm{pF}$.

The results are shown in Fig. 2. Power gain calculated using measured S-matrix presents a band-pass shape, as it has been found in measurements with battery powered devices [6]. Power gain is maximum at $60 \mathrm{MHz}$ using Electrode 1 and at $40 \mathrm{MHz}$ using Electrode 2. Propagation distance has the effect of lowering the maximum gain. On the other hand, the model proposed in [5] does not show such behavior, as it predicts an almost logarithmic relationship between power gain and frequency. In [8], a band-pass shape has been found in measurements involving a VNA and baluns, but again predicting a high pass response of the channel when battery powered small devices are involved. Moreover, the insertion of electrode inter-capacitance at transmitter and receiver side does not affect considerably the power gain. Then, the lumpedelements model of [5] seems inappropriate to describe HBC channel and electrode effects.

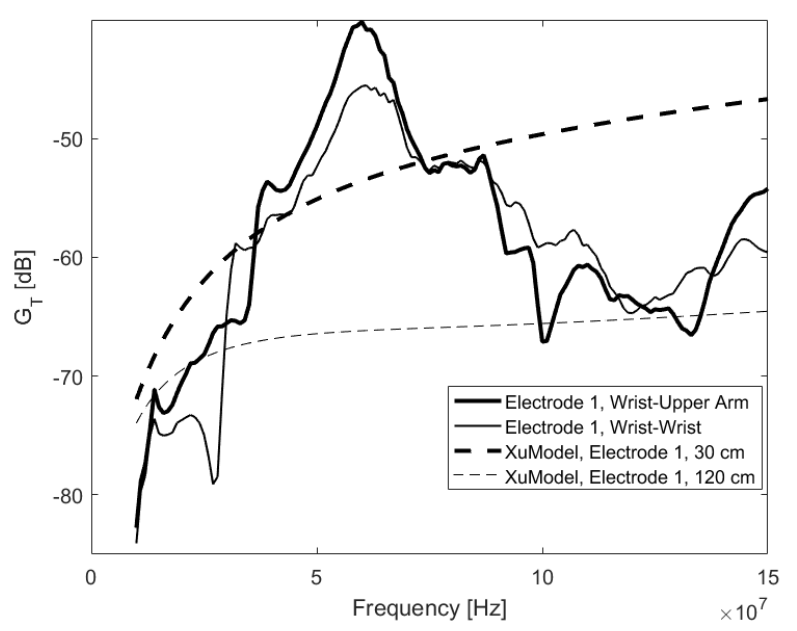

(a)

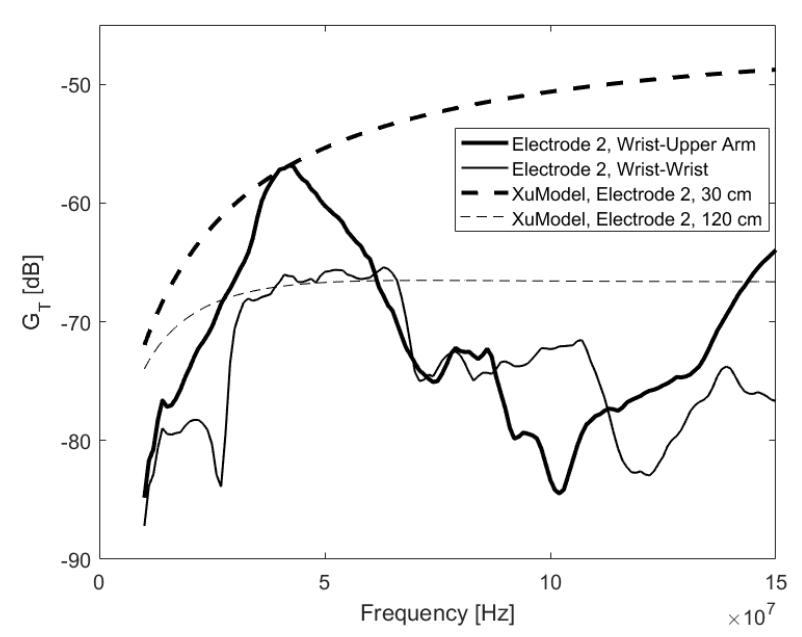

(b)

Fig. 2. Power gains obtained using measured S-matrix and lumped-elements model [5] for (a) Electrode 1 and (b) Electrode 2.

\section{A. Model}

In order to extract a practical model for $G_{T}$ from the measurement data, the elements of the Z-matrix have been fitted with rational functions, as in [6]. Rational function is :

$$
F(s)=\sum_{k=1}^{N} \frac{C_{k}}{s-A_{k}} \quad s=j 2 \pi f
$$

where $f$ is the frequency. Numerical values of $A_{k}$ and $C_{k}$ are given in Table II. $G_{T}$ curves obtained using equations (1)-(3) and values of Table I are shown in Fig. 3. 
TABLE II

PARAMETERS OF RATIONAL FUNCTIONS TO FIT Z-MATRIX ELEMENTS.

\begin{tabular}{|c|cc|cc|}
\hline \multirow{4}{*}{} & \multicolumn{4}{|c|}{ Electrode 1} \\
& \multicolumn{2}{|c|}{ Wrist-Upper Arm } & \multicolumn{2}{c|}{ Wrist-Wrist } \\
& $A_{k}$ & $C_{k}$ & $A_{k}$ & $C_{k}$ \\
\hline \multirow{2}{*}{$Z_{11}$} & $-4.47 \cdot 10^{8}$ & $15.06 \cdot 10^{10}$ & $-4.46 \cdot 10^{8}$ & $16.39 \cdot 10^{10}$ \\
& $-0.20 \cdot 10^{6}$ & $1.69 \cdot 10^{10}$ & $-0.17 \cdot 10^{6}$ & $2.05 \cdot 10^{10}$ \\
\hline \multirow{4}{*}{$Z_{21}$} & $(-0.21+j 3.91) 10^{8}$ & $(-1.89+j 0.67) 10^{10}$ & $(-0.34+j 3.90) 10^{8}$ & $(-1.55+j 0.81) 10^{10}$ \\
& $(-0.21-j 3.91) 10^{8}$ & $(-1.89-j 0.67) 10^{10}$ & $(-0.34-j 3.90) 10^{8}$ & $(-1.55-j 0.81) 10^{10}$ \\
& $-1.94 \cdot 10^{8}$ & $3.81 \cdot 10^{10}$ & $-1.42 \cdot 10^{8}$ & $1.91 \cdot 10^{10}$ \\
& $-0.67 \cdot 10^{6}$ & $0.88 \cdot 10^{10}$ & $-0.84 \cdot 10^{6}$ & $0.99 \cdot 10^{10}$ \\
\hline \multirow{2}{*}{$Z_{22}$} & $-5.11 \cdot 10^{8}$ & $12.86 \cdot 10^{10}$ & $-4.39 \cdot 10^{8}$ & $15.42 \cdot 10^{10}$ \\
& $-0.20 \cdot 10^{6}$ & $1.28 \cdot 10^{10}$ & $-0.44 \cdot 10^{6}$ & $1.60 \cdot 10^{10}$ \\
\hline \hline
\end{tabular}

\begin{tabular}{|c|cc|cc|}
\hline \hline \multirow{7}{*}{} & \multicolumn{4}{|c|}{ Electrode 2 } \\
& \multicolumn{2}{|c|}{ Wrist-Upper Arm } & \multicolumn{2}{c|}{ Wrist-Wrist } \\
& $A_{k}$ & $C_{k}$ & $A_{k}$ & $C_{k}$ \\
& & & & \\
$Z_{11}$ & $-2.73 \cdot 10^{8}$ & $4.79 \cdot 10^{10}$ & $-1.71 \cdot 10^{8}$ & $4.54 \cdot 10^{10}$ \\
& $-0.13 \cdot 10^{6}$ & $1.25 \cdot 10^{10}$ & $-0.25 \cdot 10^{8}$ & $1.18 \cdot 10^{10}$ \\
\hline \multirow{4}{*}{$Z_{21}$} & $(-0.30+j 2.70) 10^{8}$ & $(-0.70+j 0.35) 10^{10}$ & $(-0.60+j 2.63) 10^{8}$ & $(-4.20+j 2.42) 10^{9}$ \\
& $(-0.30-j 2.70) 10^{8}$ & $(-0.70-j 0.35) 10^{10}$ & $(-0.60-j 2.63) 10^{8}$ & $(-4.20-j 2.42) 10^{9}$ \\
& $-0.93 \cdot 10^{8}$ & $1.10 \cdot 10^{10}$ & $-0.94 \cdot 10^{7}$ & $-0.56 \cdot 10^{9}$ \\
& $-5.20 \cdot 10^{3}$ & $0.64 \cdot 10^{10}$ & $-0.73 \cdot 10^{6}$ & $7.48 \cdot 10^{9}$ \\
\hline \multirow{2}{*}{$Z_{22}$} & & & & \\
& $-2.77 \cdot 10^{8}$ & $5.12 \cdot 10^{10}$ & $-1.71 \cdot 10^{8}$ & $4.54 \cdot 10^{10}$ \\
& $-0.23 \cdot 10^{6}$ & $0.76 \cdot 10^{10}$ & $-0.25 \cdot 10^{6}$ & $1.18 \cdot 10^{10}$ \\
\hline
\end{tabular}

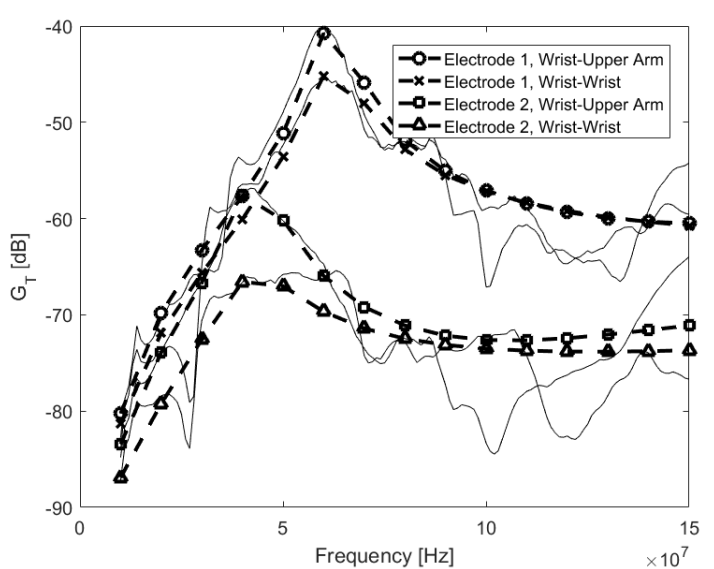

Fig. 3. Model of power gain obtained by vector fitting of Z-matrix elements.

\section{CONCLUSION}

Direct path of HBC channel has been measured with VNA and used to calculate power gain of two pairs of equivalent battery operated HCB transmitter and receiver. It has been found that power gains show a maximum, as it has been found in the literature, at $60 \mathrm{MHz}$ and $40 \mathrm{MHz}$, depending on the transmitter/receiver pair used for measurement. Results have been compared to those obtained using lumped element model of the direct path, which is insensible to the kind of device and does not show local maximum.

\section{REFERENCES}

[1] IEEE Standard for Local and metropolitan area networks, IEEE 802.15.6, 2012.

[2] N. Haga et al., "Equivalent circuit of intrabody communication channels inducing conduction currents inside the human body", IEEE Transactions on Antennas and Propagation, vol. 61, no. 5, pp. 2807-281, 2013.

[3] M. A. Callejon et al., "A comprehensive study into intrabody communication measurements", IEEE Transactions on Instrumentation and Measurement, vol. 62, no. 9, pp. 2446-2455, 2013.

[4] J. Hwang et al., "Measurement of Transmission Properties of HBC Channel and Its Impulse Response Model", IEEE Transactions on Instrumentation and Measurement, vol. 65, no. 1, pp. 177-188, 2016.

[5] R. Xu, .H. Zhu and J. Yuan, "Electric-field intrabody communication channel modeling with finite-element method", IEEE Transactions on Biomedical Engineering, vol. 58, no. 3, pp. 705-712, 2011.

[6] J. Park, H. Garudadri and P. P. Mercier, "Channel Modeling of Miniaturized Battery-Powered Capacitive Human Body Communication Systems", IEEE Transactions on Biomedical Engineering, vol. PP, no. 99, pp. 1-1, 2016.

[7] B. Kibret, A. K. Teshome and D. T. Lai, "Human body as antenna and its effect on human body communications", Progress In Electromagnetics Research, vol. 148, pp. 193-207, 2014.

[8] M. D. Pereira, G. A. Alvarez-Botero, and F. R. de Sousa, "Characterization and modeling of the capacitive HBC channel", IEEE Transactions on Instrumentation and Measurement, vol. 64, no. 10, pp. 2626-2635, 2015.

[9] S. J. Orfanidis, Electromagnetic waves and antennas. New Brunswick, NJ: Rutgers University, 2002, pp 663-683. 